\title{
Differential Neuronal Survival in the Avian Ciliary Ganglion After Chronic Acetylcholine Receptor Blockade
}

\author{
Stephen D. Meriney, ${ }^{\mathrm{a}}$ Guillermo Pilar, Masaharu Ogawa, ${ }^{\mathrm{b}}$ and Ramon Nuñez ${ }^{\mathrm{c}}$ \\ The University of Connecticut, Department of Physiology and Neurobiology, Storrs, Connecticut 06268
}

\begin{abstract}
We have described in the preceding 2 papers the development of the pharmacological and contractile properties of all targets of the ciliary ganglion: the iris and ciliary body (Pilar et al., 1987), and the choroidal coat (Meriney and Pilar, 1987). In this paper, we examine the chronic effects of ACh receptor (AChR) blockade on ciliary ganglion neuron survival. Nicotinic or muscarinic AChR blockers were administered daily to developing chicken embryos during the normal neuronal death period in the ciliary ganglion. The effects of the blockers on ganglionic and neuromuscular transmission were assessed, and neuronal survival was assayed by counting both the total number of ganglion neurons and the selectively HRP-labeled ciliary neurons after the normal neuronal death period. Blockade of ganglionic transmission decreases survival in both populations of neurons. Blockade of neuromuscular transmission increases survival in the ciliary population, which innervates the striated iris and ciliary body muscle. In contrast, blockade of synaptic activity has various influences on the survival of the choroid population, which innervates the smooth muscle of the choroid coat. Smooth muscle muscarinic receptor blockade with atropine does not influence survival. At higher doses (which block ganglionic transmission), atropine decreases choroid survival. Survival of the choroid population is increased by nicotinic blockade with $75 \mu \mathrm{g}$ alpha bungarotoxin ( $\alpha \mathrm{BTX}$ ), but decreased by 12.5 $\mu \mathrm{g} \alpha \mathrm{BTX}$. Two main conclusions arise from these studies. Activation of postsynaptic AChRs in both the ganglion and the periphery are important in the regulation of neuronal survival. These effects usually occur in opposite directions: Blockade of ganglionic transmission decreases neuronal survival, while paralysis of neuromuscular transmission increases neuronal survival. This embodies the "balance" hypothesis (Cunningham, 1982) for neuronal survival, which states that motoneurons must balance afferent and target interactlons during a critical period after synapses are formed
\end{abstract}

\footnotetext{
Received Apr. 21, 1986; revised June 8, 1987; accepted June 11, 1987.

We thank L. Landmesser, D. B. Gray, and H. Fryer for many helpful discussions and critical evaluation of the manuscript, and $S$. Putnam for assistance in the preparation of this manuscript. This work was supported by NIH 10338 , NSFBNS 8410581, The University of Connecticut Research Foundation, and an MDA fellowship to R.N. M.O. was on sabbatical leave from Kochi Medical School, Kochi, Japan.

Correspondence should be addressed to Dr. Guillermo Pilar, The University of Connecticut, Department of Physiology and Neurobiology, 75 N. Eagleville Rd., Rm. 416, Storrs, CT 06268.

a Present address: Jerry Lewis Neuromuscular Research Center, UCLA School of Medicine, 700 Westwood Plaza, Los Angeles, CA 90024

${ }^{b}$ Present address: Kochi Medical School, Okohcho, Nankoku, Kochi 781-51, Japan.

'Present address: 11 Principal Ave, Chahuites, Oaxaca, Mexico.

Copyright (c) 1987 Society for Neuroscience $0270-6474 / 87 / 123840-10 \$ 02.00 / 0$
}

in both regions. The present observations support this hypothesis. However, although both ciliary and choroid neurons have been shown to depend on the presence of the periphery for survival, target muscle paralysis via AChR blockade rescues the ciliary neurons but does not influence survival in the choroid population. Target-dependent regulation of choroid neuron survival during the normal neuronal death period is clearly different from the regulation of ciliary neuron survival.

Naturally occurring neuronal death is a widespread phenomenon in embryogenesis (see review by Cowan et al., 1984). This normally dramatic reduction in cell number can, to various degrees, be prevented by excess target tissue (Hollyday and Hamburger, 1976; Boydston and Sohal, 1979), trophic factor (Hamburger and Yip, 1984), or blockade of the neuromuscular junction (Pittman and Oppenheim, 1978).

It is generally accepted that the survival of motoneurons is dependent on the targets they innervate (Hamburger, 1934; Beaudoin, 1955; Pilar et al., 1980). During development, motoneurons may compete for a finite number of synaptic sites or for a limited supply of trophic factor produced by the target. Although these possibilities are not necessarily exclusive, many researchers propose that the amount of trophic factor produced or released by the target directly regulates neuronal survival. This hypothesis is supported by studies of NGF, which has been shown to influence sensory and sympathetic neuron survival (Levi-Montalcini and Angeletti, 1963). If motoneurons compete for trophic support within the target region, and because it is known that even those motoneurons that will eventually die do make neuromuscular contacts (Landmesser and Pilar, 1974; Oppenheim and Chu-Wang, 1977), it is of interest to know which aspects of neuromuscular synapse formation are important for long-term neuronal survival; is synaptic activity a critical factor, or is contact with a specific component of the target sufficient to prevent neuronal death? Pittman and Oppenheim (1978) addressed this question by pharmacologically blocking neuromuscular transmission during the neuronal death period, dramatically reducing the amount of motoneuron death. This treatment did not prevent anatomical synapse formation, and Pittman and Oppenheim (1979) conjectured that synaptic transmission acts in the target region to regulate the availability of a putative trophic factor.

Blockade of motoneuron afferent activation has also been shown to influence survival during the normal neuronal death period. Surgical denervation can decrease neuronal survival in the ciliary ganglion (Levi-Montalcini, 1949; Furber and Oppenheim, 1984) and in the lateral motor column of the spinal cord (Okada and Oppenheim, 1984). In addition, Wright (1981) 
has demonstrated that selective pharmacological blockade of the ganglionic (afferent) synapses in the ciliary ganglion can also decrease neuronal survival during the normal neuronal death period. Therefore, both peripheral and central mechanisms may be regulating neuronal survival.

We have evaluated these factors in the ciliary ganglion, where the ontogeny of target receptor pharmacology is known and the effects of drug application on synaptic transmission at both ganglionic and neuromuscular synapses can be accurately measured. The chick ciliary ganglion consists of only 2 populations of cholinergic motoneurons (ciliary and choroid), which receive cholinergic input from the avian homolog of the Edinger Westphal nucleus and project separately to their respective target tissues. Also present in these neurons are endogenous peptides (opiates and substance P) (Erichsen et al., 1982). Ciliary cells project to the striated iris muscle and ciliary body, while choroid cells project to the smooth muscle of the choroid coat. Both populations of ciliary ganglion cells normally decrease by about $50 \%$ during synapse formation with the target (Landmesser and Pilar, 1974).

Having completed a characterization of the contractile and pharmacological properties of the choroid neuromuscular synapses in the previous paper (Meriney and Pilar, 1987), and of the iris and ciliary body neuromuscular synapses in the first paper in this series (Pilar et al., 1987), we can now evaluate the results of neuromuscular transmission blockade on neuronal survival. ${ }^{1}$ To facilitate the comprehension and interpretation of the data presented in this paper we will briefly summarize our findings on the developmental receptor pharmacology at these target muscles and ganglionic synapses. Choroid neuromuscular transmission is mediated by muscarinic AChRs only (Meriney and Pilar, 1987). Iris and ciliary muscles are also muscarinic at the beginning of the neuronal death period [stages (St) 34-36], but nicotinic neuromuscular junctions form halfway through this period despite the retention of muscarinic receptors on these muscle fibers (Pilar et al., 1987). Since cholinergic transmission is also present at ganglionic synapses, some of the drugs used may be acting at these synapses. It is known that adult ganglionic transmission is nicotinic at both ciliary and choroid synapses (Marwitt et al., 1971), and that muscarinic receptors are present in the ganglion, but are probably extrasynaptic (G. Pilar, unpublished observations). The ganglion is known to contain binding sites for $\alpha \mathrm{BTX}$ (a nicotinic ligand) and quinuclidinyl benzylate (QNB; a muscarinic ligand) (Chiappinelli and Giacobini, 1978; I. S. McLennan and G. Pilar, unpublished observations). Electrical transmission also has been demonstrated at ciliary ganglionic synapses, but appears only after the period of normal neuronal death (Landmesser and Pilar, 1972).

The rationale for using the ciliary ganglion to investigate the role of activity in normal neuronal death is 2-fold: (1) In the same ganglion, we can compare 2 independent populations of motoneurons, which have different types of target tissues with separate receptor-activation pharmacologies, and (2) we can control for the effects of afferent activity. Neurons that innervate smooth muscle are rarely found in discrete populations, thus making experimental manipulation and analysis difficult. The ciliary ganglion is one preparation in which thesc studics arc

$\mathrm{i}$ The dilator fibers of the iris are probably not involved in the competition for survival during the normal neuronal death period (St 34-40), since they first appear after this period (Pilar et al., 1987). The developing iris muscle can also be activated by light (Pilar et al., 1987). However, since the embryos were kept in a dark incubator, this form of muscular activation was not a factor. possible. In this paper, we extend the observations made on the cffects of AChR blockade on neuronal survival in the spinal cord. Our data confirm some of the observations made on the role of activity at striated muscle synapses, but raise questions concerning the general applicability of this hypothesis to different neuronal populations innervating nonskeletal muscle targets. Some of this work has been presented in abstract form (Meriney et al., 1984).

\section{Materials and Methods}

Estimation of ganglion cell numbers. Chicken cmbryos werc killcd at St 40 [embryonic day (E) 14] and ciliary ganglia were processed in one of 2 ways. Neuronal cells were counted in ciliary ganglia that had been fixed in Bouin's, sectioned in paraffin at $8 \mu \mathrm{m}$, and stained with hematoxylin/eosin orange. Differential cell counts of ciliary neurons were made after selective labeling with HRP. Ciliary and choroid cells can be identified by their size, position of the nucleus, and position in the ganglion. However, these criteria are not completely reliable because there is an overlapping population of ganglion neurons with intermediate characteristics. For this reason, retrograde identification is necessary for an accurate quantitative assessment. Ciliary ganglia were removed intact with iris and ciliary body musculature by cutting away all choroid target tissue and severing all choroid nerves exiting the ganglia. The iris and ciliary body were bathed in 5\% HRP for $1 \mathrm{hr}$ to allow selective uptake of the HRP by the ciliary nerve terminals. The preparation was incubated in oxygenated Tyrode's solution at $33^{\circ} \mathrm{C}$ for $5 \mathrm{hr}$ to allow for retrograde transport of the HRP to ciliary cell somas in the ganglia. This technique has been shown to label all innervating neurons (Pilar et al., 1980). Ganglia were fixed in $2 \%$ glutaraldehyde overnight, washed in Tris buffer for $7 \mathrm{~d}$, and reacted with diaminobenzidene before paraffin sectioning at $8 \mu \mathrm{m}$. Cells with a distinct granular HRP reaction product were counted as ciliary cells (see Fig. 1). Sections were counterstained with cresyl violet. However, cresyl violet counterstaining of HRP-labeled ganglia, which did not obscure the HRP reaction product, was too weak for making reliable direct counts of choroid cells. The number of choroid cells in HRP-stained ganglia was obtained indirectly by subtracting the number of HRP-labeled ciliary cells from the total cell number counted after hematoxylin/eosin orange staining of the contralateral ganglia. All counting was done $\times 400$ and corrected for double counting (Abercrombie, 1946).

Counts of neurons were made in ciliary ganglia isolated from control and drug-treated White Leghom chicken embryos after development to the desired stage (Hamburger and Hamilton, 1951). The drugs, dissolved in sterile isotonic saline, were administered daily in 50-100 $\mu$ l volumes to the chorioallantoic membrane of the egg on E7-E14 through a window cut in the shell of the egg. In the absence of information on drug absorption, diffusion, or subsequent compartmentalization within the egg, effective concentrations were estimated by assuming a simple dilution into an egg volume of about $40 \mathrm{ml}$. The effectiveness of the nicotinic neuromuscular blockers was measured by monitoring the spontaneous frequency of discrete hindlimb kicks. Curare $(2 \mathrm{mg} / \mathrm{d})$ and $\alpha$ BTX $(75$ $\mu \mathrm{g} / \mathrm{d}$ ) reduced hindlimb kicks from a control value of $15 / \mathrm{min}$ to 0.37 $\min$. Atropine $(0.15 \mathrm{mg} / \mathrm{d})$ was used at a concentration that has been shown to block iris contractions (St 36) (see Pilar et al., 1987).

Measurements of ganglionic transmission. To study the ganglionic effects of these drugs during the normal neuronal death period, we monitored transmission through the ganglion in the presence and absence of AChR blockers by recording postganglionic responses to preganglionic nerve electrical stimulation. The ciliary ganglion was removed intact, with an adequate length of preganglionic oculomotor nerve and postganglionic ciliary and choroid nerves to be used for extracellular stimulation and recording (see Landmesser and Pilar, 1972, for details). During bath-application of $\alpha \mathrm{BTX}, d$-tubocurarine chloride (dTC), and atropine, the preganglionic nerve was stimulated with suprathreshold single electrical pulses. Electrical activity in postganglionic ciliary and choroid nerves was monitored separately with extracellular suction electrodes.

Pupillomorphic measurements of iris contractions. In many of the embryos used for estimations of the total number of neurons, the effects of chronic application of the drugs on iris neuromuscular transmission were assessed. A circular piece of sclera, to which the iris and ciliary body are attached, was removed intact with the ciliary nerves. A suction electrode was used to stimulate the ciliary nerves at $50 \mathrm{~Hz}$ for $3 \mathrm{sec}$, 


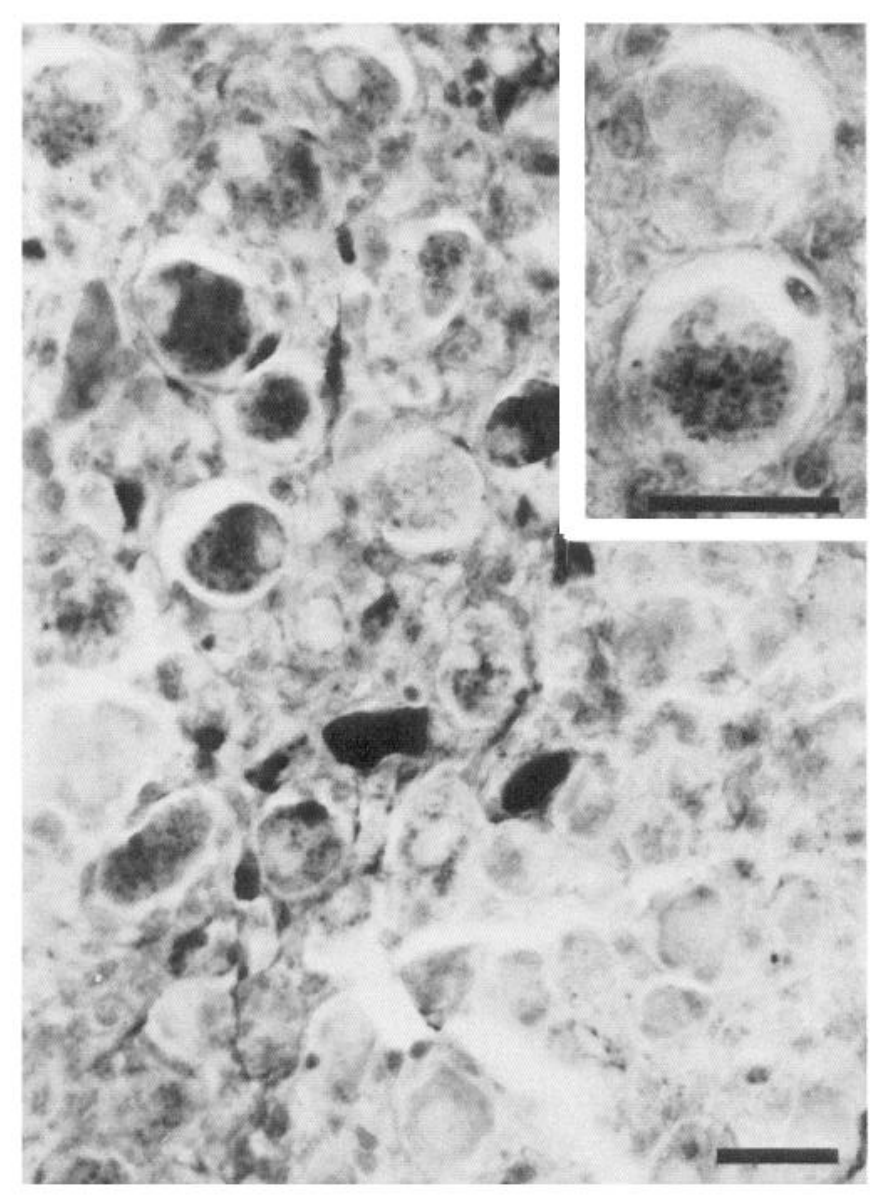

Figure 1. Stage 40 HRP-labeled ciliary ganglion $(\times 400)$. Ciliary cells contain a granular HRP reaction product; choroid cells are counterstained with cresyl violet. Note the large pocket of choroid cells in the lower right corner. Inset $(\times 630)$, Labeled ciliary cell adjacent to an unlabeled and counterstained choroid cell. Calibration, $10 \mu \mathrm{m}$.

and the tetanic contraction of the iris was photographed during its maximum response. The area of the pupil in drug-treated and in control irises was compared with the area of the pupil in the relaxed iris (see Pilar et al., 1987, for details).

Culture of ciliary ganglion neurons. To further evaluate the chronic effects of atropine on neuronal survival, E8 (St 34) ciliary ganglion neurons were cultured as previously described (Tuttle et al., 1980) after trypsinization ( $0.08 \%$ in CaMg-free Tyrode's) and trituration. The neurons were grown in standard media consisting of $80 \mathrm{ml}$ modified Eagle's medium (MEM), $10 \mathrm{ml}$ heat-inactivated horse serum, $10 \mathrm{ml} 50 \%$ chick embryo extract, $1 \mathrm{ml} 100 \times$ MEM vitamin mix (Gibco, Chagrin Falls, $\mathrm{OH}$ ), and $2 \mathrm{ml} 50 \times$ amino acid mix (Gibco). Atropine sulfate (Sigma Chemical Co., St. Louis, MO) was added to the culture media at varying concentrations, and the neurons in both control and drug-treated cultures were counted every day under phase optics $(\times 40)$.

\section{Results}

\section{Ciliary ganglion neuron apportionment}

The ciliary ganglion has 2 main populations of neurons, ciliary and choroid. It is possible to divide the ciliary neurons into 2 subpopulations that innervate 2 different target organs: the iris and the ciliary body. From our own estimation of the number of ciliary axons and the distribution of these axons in the 2 targets (see Zenker and Krammer, 1967), it is possible to appraise the number of neurons innervating the ciliary body and iris. We estimate that before the cell death period (St 34), 3875 choroid, 792 iris muscle ciliary cells, and 1583 ciliary body

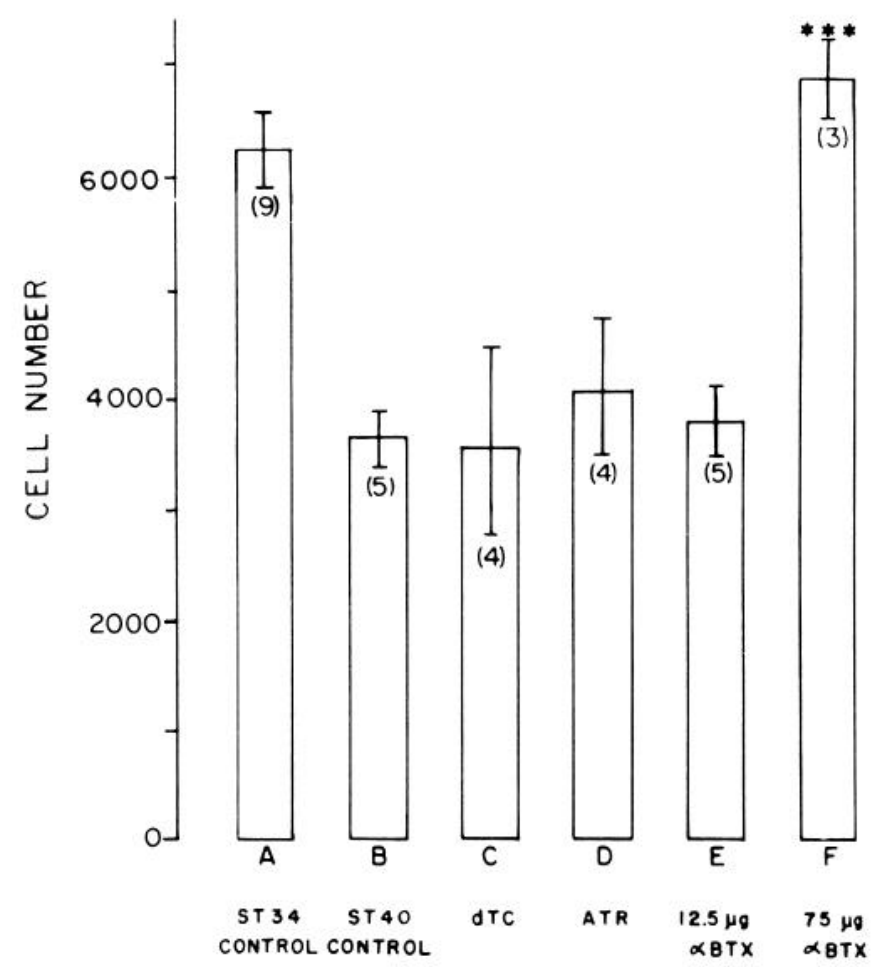

Figure 2. Total neuronal number in the ciliary ganglion after $\mathrm{AChR}$ blockade by atropine, dTC and $\alpha \mathrm{BTX}$. ${ }^{* * *}$ Significantly different from St 40 control value $(p<0.01)$ after a 1-way analysis of variance using Tukey's test for pairwise comparisons.

ciliary cells are present. After St 40, only 2247 choroid, 450 iris muscle ciliary, and 920 ciliary body ciliary cells remain. These figures are compared with the results obtained from pharmacological blockade experiments.

\section{Modification of total ganglion cell number by AChR blockade}

The influence of pharmacological synaptic blockade on neuronal survival was assessed following the chronic application of nicotinic and muscarinic antagonists to chick embryos. These treatments have been shown not to prevent the formation of anatomically identified neuromuscular contacts (Freeman et al., 1976; Sohal et al., 1979), but simply to prevent their function. After $7 \mathrm{~d}$ of AChR blockade, the neurons in the ciliary ganglion were counted. Control ganglia had a total of 3703 neurons after the cell death period (St 40). Chronic AChR blockade with atropine $(0.15 \mathrm{mg} / \mathrm{d})$, curare $(2 \mathrm{mg} / \mathrm{d})$, or $\alpha$ BTX $(12.5 \mu \mathrm{g} / \mathrm{d}) \mathrm{did}$ not significantly change the total cell number after the normal cell death period (Fig. 2). Atropine-treated embryos had 4057 ganglion cells, curare-treated embryos had 3559 ganglion cells, and $\alpha$ BTX-treated embryos had 3736 ganglion cells. In contrast, daily AChR blockade with a higher dose of $\alpha$ BTX $(75 \mu \mathrm{g} / \mathrm{d})$ dramatically increased cell survival (95\%), leaving 6866 ganglion cells (Fig. 2).

Because of the apparent lack of effect on neuronal survival of most of the drug treatments (atropine, dTC, and low-dose $\alpha$ BTX) (Fig. 2), we considered the possibility that the total cell number was influenced by a limited supply of trophic factor within the ganglion itself, rather than by the amount of trophic factor supplied by the target. But this interpretation appears unlikely on the basis of earlier studies (Pilar et al., 1980). If the ganglion itself has a limited amount of trophic factor and can support 
only about 3700 neurons, and if one group of neurons is removed, we would expect increased survival in the other population. Yet, when the ciliary nerves are axotomized before the normal cell death period, about $80 \%$ of the ciliary cells die, while the remaining choroidal population exhibits a normal $50 \%$ reduction in cell number (Pilar et al., 1980). The increased ciliary cell death does not result in more choroidal cell survival. This observation implies that competition for trophic support is not in the ganglion, but in the target regions. Therefore, since the ciliary and choroid neuronal populations innervate different targets, both populations would be expected to compete independently for survival.

\section{Differential cell number}

When the ciliary and choroid populations were identified histologically by labeling with HRP, it became clear that, although the dTC, atropine, and low-dose $\alpha$ BTX (12.5 $\mu \mathrm{g} / \mathrm{d})$ treatments did not significantly affect total neuron survival in the ganglion, the 2 populations of ganglion cells were affected differently by these drug treatments. These experiments are illustrated in Figure 3. Control ganglia contained 1379 ciliary cells and 2247 choroid cells after the normal cell death period. Daily dTC treatment, which blocks nicotinic receptors in the ganglion, iris, and ciliary body, resulted in the survival of 1885 ciliary cells (a $36 \%$ increase in survival), while choroid cell survival decreased by 1674 cells $(25 \%)$. Chronic muscarinic blockade by atropine, which blocks functional activity at the choroid neuromuscular junction and the early iris and ciliary body neuromuscular junction, increased ciliary cell survival by $71 \%$, leaving 2359 ciliary cells, while, surprisingly, choroid cell survival decreased by $25 \%$, leaving 1698 choroid cells.

$\alpha$ BTX blocks functional transmission only at the iris and ciliary body neuromuscular junction. After chronic low doses $(12.5 \mu \mathrm{g} / \mathrm{d})$ of $\alpha \mathrm{BTX}$, ciliary cell survival increased by $50 \%(2074$ ciliary cells), while choroid cell survival decreased by $26 \%$ (1662 choroid cells). AChR blockade with the higher dose $(75 \mu \mathrm{g} / \mathrm{d})$ of $\alpha$ BTX demonstrated a dose-dependent effect by preventing almost all ciliary cell death: 2600 ciliary cells survived the normal death period (an $89 \%$ increase in survival). Surprisingly, choroid cell survival increased similarly (100\%), leaving 4266 choroid cells.

Because several of these results were unexpected and could not have been predicted solely on the basis of target interactions, we decided to investigate the acute and chronic effects of the AChR blockers at developing ganglionic synapses. Although we knew that preganglionic blockade could decrease neuronal survival, we felt initially that this was not a complicating factor, since neither $\alpha \mathrm{BTX}$ nor atropine was able to acutely block the adult ganglionic synapse (Marwitt et al., 1971). However, since the pharmacology of the developing synapses in the ciliary ganglion is largely unknown, we investigated the effects of AChR blockers on these embryonic ganglionic synapses.

\section{Pharmacology of developing ganglionic synapses}

To determine the effects of $\alpha \mathrm{BTX}, \mathrm{dTC}$, and atropine on ciliary and choroid ganglionic synapses, extracellular recordings of ganglionic transmission were made after acute administration of these drugs to isolated ganglia (Fig. 4). For all ages examined (St 38-hatch), only dTC $(10 \mu \mathrm{M})$ was able to completely block transmission across both ciliary (Fig. $4 B$, upper trace) and choroid (Fig. $4 B$, lower trace) synapses. Surprisingly, atropine (10

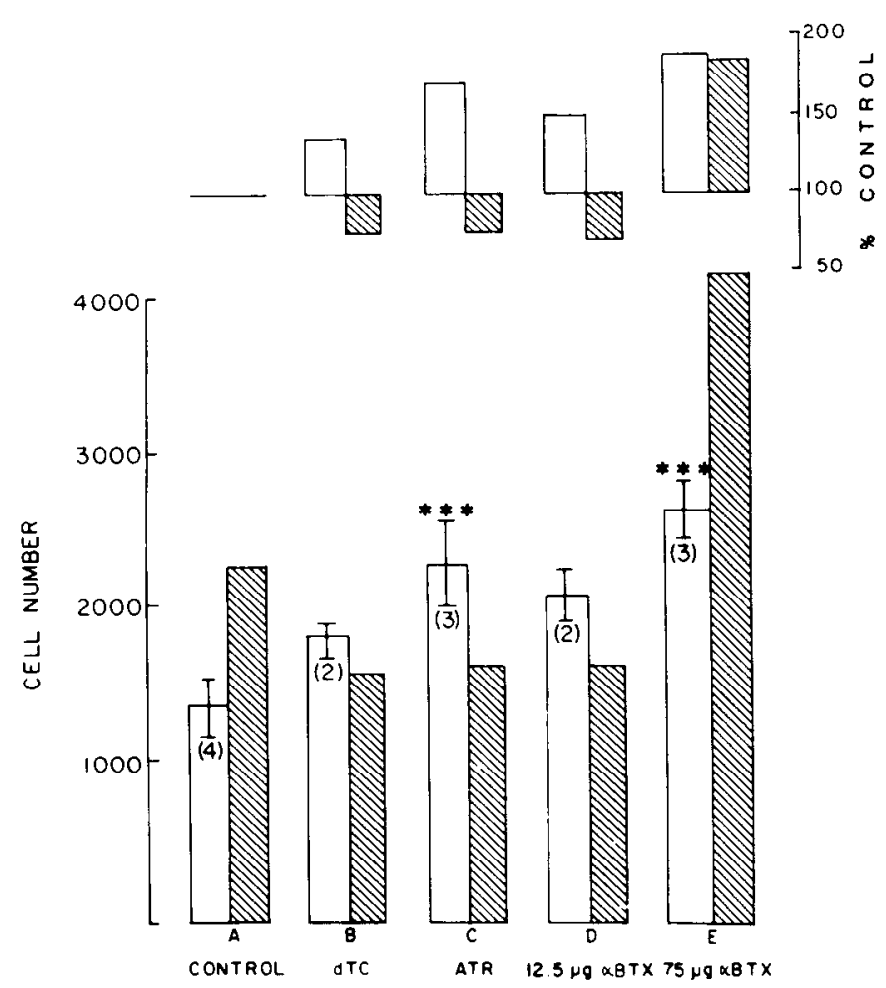

Figure 3. Differential neuronal number in the ciliary ganglion after AChR blockade by atropine, dTC, and $\alpha$ BTX. Open bars, ciliary cells; hatched bars, choroid cells. ${ }^{* * *}$ Significantly different from control value $(p<0.01)$ after a 1-way analysis of variance using Tukey's test for pairwise comparisons. The upper graph shows the percentage changes of each population with respect to control.

$\mu \mathrm{M})^{2}$ partially blocked ciliary transmission and completely blocked choroid ganglionic transmission at early (St 36-38) embryonic ages (Fig. $4 F$ ). This is contrary to observations made of mature synapses, where atropine does not block ganglionic synaptic transmission in either population (Marwitt et al., 1971). Transmission through the adult ciliary ganglion was influenced only by curare, a nicotinic AChR blocker. Atropine either may be acting on novel muscarinic ganglionic receptors or, as has been demonstrated with micromolar concentrations of this drug in adult frog ganglia (Connor et al., 1983), it may be directly blocking synaptic current. Since choroid ganglionic synapses are made with small boutons (as opposed to the large, calycal synapses onto ciliary cells), it is likely that these choroid synapses are more susceptible to transmission blockade. Furthermore, ganglionic transmission in older embryos (St 39-hatch) was less susceptible to blockade by atropine. It is possible that ganglionic receptors involved in transmission change their distribution or their affinity characteristics during development. However, regardless of the mechanism of action, the atropine treatment $(0.15 \mathrm{mg} / \mathrm{d})$ completely blocked choroid synapses and partially blocked ciliary synapses.

To overcome this unexpected blockade with $0.15 \mathrm{mg} / \mathrm{d}$ atropine, some experiments were performed with a lower dose of atropine, which does not block ganglionic transmission. We performed experiments that showed that $1 \mu \mathrm{M}(0.015 \mathrm{mg} / \mathrm{d})$ atropine did not block ganglionic transmission (not shown),

\footnotetext{
${ }^{2}$ Given simple diffusion of atropine into an egg volume of $40 \mathrm{ml}$, one daily injection is estimated to reach an effective concentration of $5 \mu \mathrm{M}$.
} 


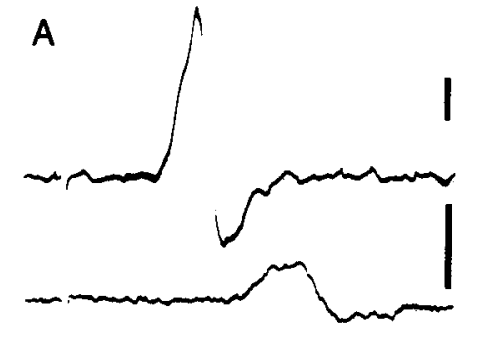

B

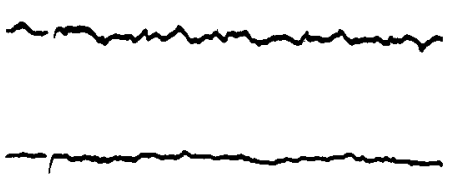

$\mathrm{C}$

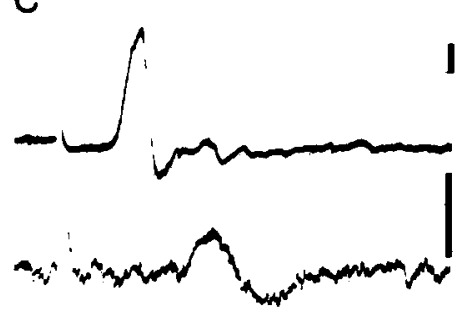

D
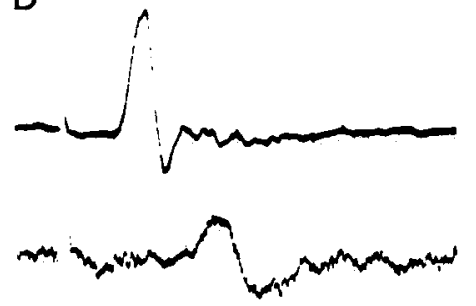

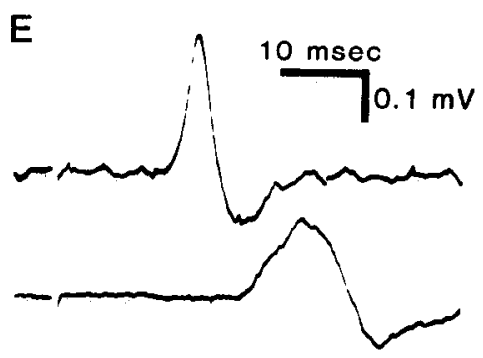

$\mathbf{F}$
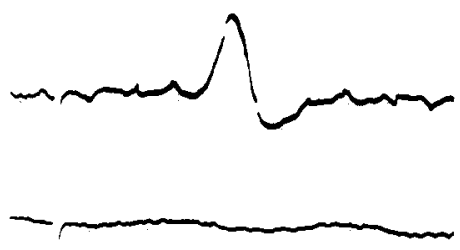

Figure 4. Effect of $\mathrm{dTC}, \alpha \mathrm{BTX}$, and atropine on St 38 ganglionic transmission across ciliary (upper traces) and choroid (lower traces) synapses. $A$, Control. $B, \mathrm{dTC}, 10 \mu \mathrm{M}$, completely blocks both synapses. $C$, Control. $D, \alpha \mathrm{BTX}, 3 \mu \mathrm{g} / \mathrm{ml}$, does not influence transmission across either synapse. $E$, Control. $F$, Atropine, $10 \mu \mathrm{M}$, partially blocks ciliary transmission and completely blocks choroid transmission. Differences in response latency between treatment groups $A, C$, and $E$ are due to variations in recording distance from the ganglion between preparations. All vertical calibrations, $0.1 \mathrm{mV}$.

while $10 \mu \mathrm{M}(0.15 \mathrm{mg} / \mathrm{d})$ atropine did (see Fig. 4). To determine whether the decrease in choroid survival was due to ganglionic blockade, total cell number was evaluated with a 10 -fold lower dose of atropine (a dose that blocks peripheral muscarinic receptors). Following this low-dose atropine treatment, $4568 \pm$ 67 neurons were alive in the ciliary ganglion at $\mathrm{St} 40$ (compared to $4057 \pm 332$ following the higher dose of atropinc). This increase in neuronal survival of approximately $20 \%$ was likely due to the removal of ganglionic transmission blockade, which resulted in increased choroid cell death (again, approximately $20 \%$ ). Nevertheless, despite the removal of the atropine-induced ganglionic blockade, there appeared to be no increase (compared to controls) in choroid survival following peripheral paralysis; in other words, the proportion of choroid neurons that died was similar to the proportion that would normally have died.

$\alpha$ BTX $(3 \mathrm{mg} / \mathrm{ml}$ ) had no effect on either ciliary or choroid ganglionic transmission (Fig. $4 D)$. High doses $(10.5 \mu \mathrm{g} / \mathrm{ml})$ of $\alpha$ BTX only slightly increased the latency of transmission across ciliary and choroid synapses (not shown). The slight effect of high doses of $\alpha$ BTX may have been due to the presence of toxin impurities in the $\alpha$ BTX (obtained from Sigma), which have been shown to block transmission through the ciliary ganglion (Chiappinelli and Zigmond, 1978; Loring et al., 1984).

\section{Chronic $\alpha B T X$ and atropine treatment}

Ganglionic synapses were not blocked even by chronic treatment with the highest dose of $\alpha \mathrm{BTX}$. Treatment of the chick embryo with $75 \mu \mathrm{g} / \mathrm{d}$ of $\alpha \mathrm{BTX}$ (the dose used to prevent neuronal death in the spinal cord; Pittman and Oppenheim, 1978) for 7-10 d did not block ganglionic transmission across either ciliary or choroid synapses (Fig. 5).

It was found, after acute application, that treatment with 0.15 $\mathrm{mg} / \mathrm{d}$ of atropine for $6 \mathrm{~d}$ (the dose used to increase ciliary cell survival and decrease that of choroid cells) partially blocked ciliary ganglionic transmission, and completely blocked choroid transmission at St 40 (Fig. 6A). Figure $6 B$ demonstrates that the effects of chronic atropine treatment on ganglionic trans- mission can be washed out. Figure $6 B$, upper record is from a chronically treated ganglion removed from the embryo and placed in Tyrode's solution containing $10 \mu \mathrm{M}$ atropine. After St 40, however, choroid ganglionic transmission was only partially blocked by atropine. Atropine became less effective in blocking transmission as the synapses matured. These unusual variations in receptor pharmacology during development, which certainly deserve further study, forced us to modify the predicted sites of action of some of the AChR blockers used in this study, and, subsequently, our hypotheses on how these agents might affect neuronal survival.

We made pupillomorphic measurements of iris contractions after $7 \mathrm{~d}$ of atropine treatment, to determine the effect of this muscarinic AChR antagonist on ciliary nerve transmission in the iris at St 40 . A contracture, elicited following $50 \mathrm{~Hz}$ stimulation, was completely blocked by $\alpha \mathrm{BTX}$. Therefore, the chronic dose of atropine used to influence neuronal survival does not influence nicotinic activation of the iris at $\mathrm{St} 40$. On the other hand, at St 37, following the same chronic atropine application, ciliary nerve stimulation evoked no contracture.

\section{Effects of atropine on cultured ciliary ganglion neurons}

As described above, atropine caused a decrease in neuronal survival in the choroid population. It is possible that the high dose used (about $5 \mu \mathrm{M} / \mathrm{d}$ ) may have had a direct toxic effect on the developing neurons. As a control for this possibility, atropine $(10 \mu \mathrm{M})$ was applied every second day to dissociated ciliary ganglion cells in culture. Figure 7 illustrates that at $10 \mu \mathrm{M}$ (filled circles), neuronal survival was similar to that of untreated controls (open circles). At concentrations higher than $100 \mu \mathrm{M}$, the drug decreased neuronal survival. Figure 7 also shows (triangles) that a single application of $500 \mu \mathrm{M}$ atropine to a 2-d-old culture for $2 \mathrm{hr}$ caused permanent damage to the neurons, such that by day 10 in culture, all neurons had died. These lethal effects of atropine may be similar to those of local anesthetics and TTX, which at high doses cause the death of cultured neurons (Bergey et al., 1981). From these observations, we conclude that at the 


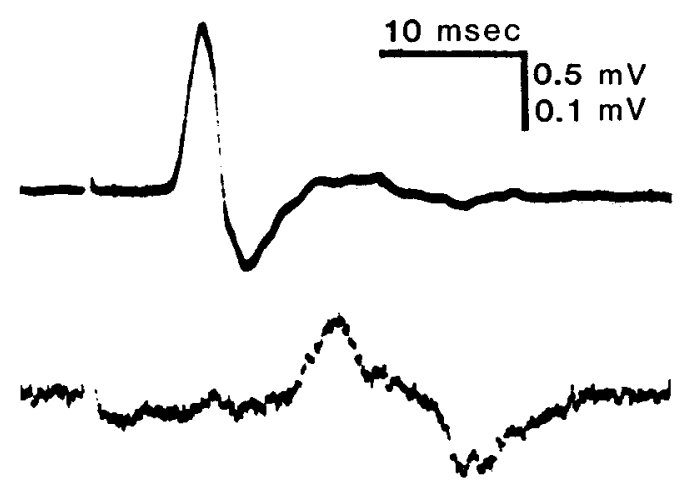

Figure 5. Effect of $9 \mathrm{~d}$ of chronic (75 $\mu \mathrm{g} / \mathrm{d}) \alpha \mathrm{BTX}$ treatment on ciliary (upper trace) and choroid (lower trace) ganglionic transmission ( $\mathrm{St} 42)$. $\alpha \mathrm{BTX}$ was never able to significantly block ganglionic transmission at either synapse.

doses that we estimate to be effective in the embryo (see footnote 2 ), there is no toxic effect on ganglion cells. Moreover, atropine enhanced survival of neurons in one population and decreased it in another - a further indication that cytotoxicity was not a factor in these experiments.

\section{Discussion}

Since each population of ciliary ganglion neurons has a different peripheral cholinergic pharmacology, and since each competes independently for survival, these populations will be discussed separately.

\section{Ciliary cell survival}

Blockade of synaptic activity during the cell death period can predictably influence survival in the ciliary population. Pharmacological blockade of ganglionic transmission decreases neuronal survival, while blockade of neuromuscular transmission increases neuronal survival. Chlorasondamine, a ganglionic blocker, decreases ciliary cell survival by $25 \%$ (Wright, 1981). $\alpha \mathrm{BTX}$ and atropine, both of which block neuromuscular transmission, increasc ciliary ccll survival by as much as $89 \%$ and $71 \%$, respectively.

$\alpha$ BTX blocks the nicotinic AChRs that predominate in the striated muscle at the ciliary neuromuscular junction during the last portion of the cell death period. Since muscarinic AChRs predominate at the ciliary neuromuscular junction during the early portion of the neuronal death period, it is not surprising that atropine also increase (by $71 \%$ ) ciliary neuron survival. ${ }^{3}$

The low dose of $\alpha \mathrm{BTX}(12.5 \mu \mathrm{g} / \mathrm{d})$ may have only a moderate effect on ciliary cell survival; several days of injection are required to produce a complete neuromuscular block ( $\alpha$ BTX produces a relatively irreversible $\mathrm{AChR}$ blockade). Given dilution into a $40 \mathrm{ml}$ egg volume, this daily injection is roughly equal to $0.3 \mu \mathrm{g} / \mathrm{ml} \alpha \mathrm{BTX} / \mathrm{d}$. Isolated iris preparations require $1 \mu \mathrm{g} /$ $\mathrm{ml}$ for complete neuromuscular blockade (Pilar et al., 1987). If several days of low-dose $\alpha$ BTX treatment are required for complete muscular paralysis, a moderate effect on neuronal survival may be expected. The higher daily dose $(75 \mu \mathrm{g} / \mathrm{d})$ dilutes to

\footnotetext{
${ }^{3}$ We do not know if prolonged atropine treatment can maintain this ciliary neuron survival after $\mathrm{St} 40$. However, since it has been shown that muscarinic receptors do not significantly contribute to nerve-evoked muscular activity in the iris after St 39 (Pilar et al., 1987), it seems unlikely that prolonged atropine treatment could continue to maintain the increased ciliary neuron survival after St 40 . These long-term analyses are in progress.
}
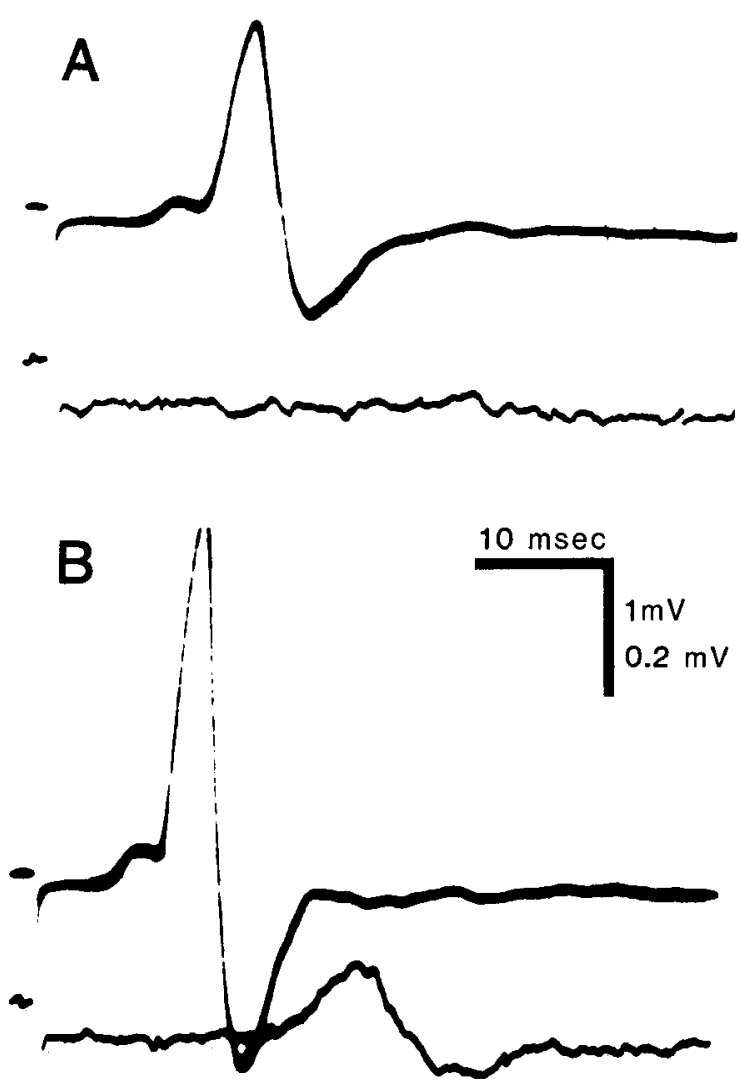

Figure 6. Effect of $6 \mathrm{~d}$ of chronic $(0.15 \mathrm{mg} / \mathrm{d})$ atropine treatment on ciliary (upper traces) and choroid (lower traces) ganglionic transmission (St 40). $A$, In the chronically treated ganglia, rapidly (in less than 10 min) dissected in $3 \mu \mathrm{M}$ atropine, the ciliary transmission persists, while the choroid transmission is completely blocked. $B$. After the preparation is washed for $1 \mathrm{hr}$, the ciliary transmission increases in amplitude, and the choroid transmission returns.

about $2 \mu \mathrm{g} / \mathrm{ml}$ in the egg, and would be expected to cause muscle paralysis after only one injection.

Interestingly, dTC, which blocks both ganglionic and neuromuscular synapses, increases neuronal survival by $36 \%$. This increase in survival is smaller than that seen after atropine or $\alpha$ BTX treatments, which may be due to the opposing consequences of both ganglionic and neuromuscular blockade in the ciliary cell-striated muscle system. Neuromuscular activity blockade in the iris and ciliary body may increase "support" to developing ciliary ganglion cells sufficiently to prevent the ganglionic blockade from decreasing neuronal survival.

The ciliary cell-striated muscle system reponse to neuromuscular blockade during the cell death period is similar to that seen in the lateral motor column of the spinal cord (Pittman and Oppenheim, 1978, 1979). Blocking the striated neuromuscular synapse appears to increase support to developing motoneurons, decreasing the normal neuronal death. On the other hand, blocking transmission through the ciliary ganglion causes an increase in cell death during the normal neuronal death period. This effect can be overridden to some degree by simultaneous neuromuscular blockade in the striated target musculature (decreasing cell death after dTC treatment, which completely blocks both synapses). Okado and Oppenheim (1984) have also observed that dTC treatment can override the effects of surgical afferent denervation, increasing motoneuron survival. 


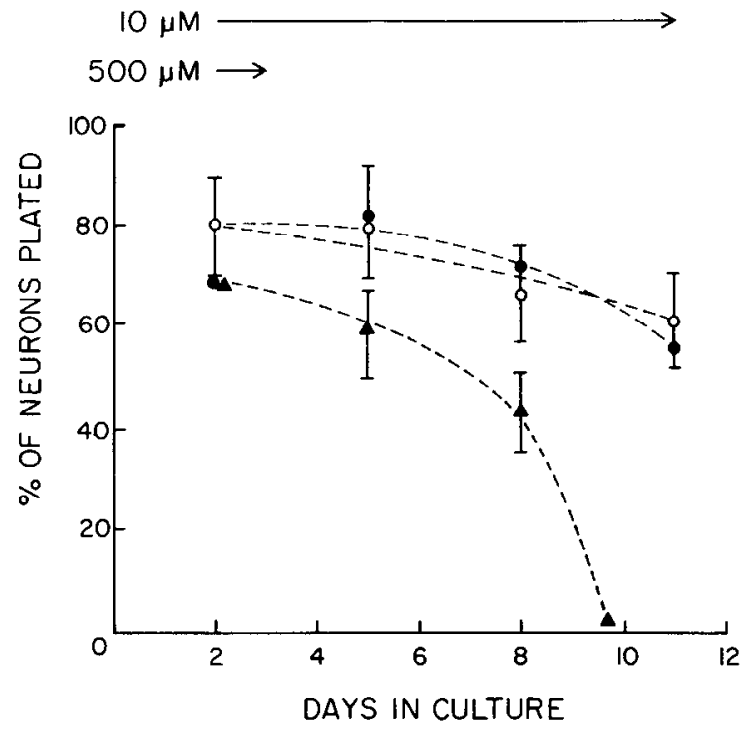

Figure 7. Toxic effects of atropine on cultured ciliary ganglion neurons. Neuronal survival is plotted after $10 \mu \mathrm{M}$ atropine (filled circles) administration. The drug was applied every other day to the culture media, and neuronal survival was not different from control (open circles). A $2 \mathrm{hr}$ exposure to $500 \mu \mathrm{M}$ atropine (triangles) on the second day of culture decreased neuronal survival such that after $10 \mathrm{~d}$, no neurons were alive.

\section{Choroid cell survival}

Blockade of synaptic activity during the cell death period has various influences on the survival of the choroid population, depending on the drug used. Consistent with the hypothesis that blockade of ganglionic transmission decreases neuronal survival, chlorasondamine (Wright, 1981) and dTC, both of which block only ganglionic transmission in the choroid, decrease neuronal survival by about $25 \%$.

However, blocking choroid ganglionic synapses does not always decrease choroid neuron survival. For example, morphine has been shown to increase choroid cell survival despite its ability to block choroid ganglionic transmission during the normal neuronal death period (Meriney and Pilar, 1985; Meriney et al., 1985). Ganglionic blockade may decrease neuronal survival unless overridden by other factors acting to increase neuronal survival.

Unlike blockade in the ciliary cell system, that of choroid neuromuscular transmission does not result in increased survival of the innervating motoneurons. Daily muscarinic AChR blockade with $0.15 \mathrm{mg} / \mathrm{d}$ atropine was estimated to require an approximately 10 -fold greater $(10 \mu \mathrm{M})$ dose than was required to paralyze muscarinic transmission. The $10 \mu \mathrm{M}$ dose was used initally to ensure complete paralysis in the egg. However, when choroid survival was examined at the end of the normal neuronal death period, a decrease of $25 \%$, compared to controls, was observed. This is in contrast to the effects of atropine, $\alpha \mathrm{BTX}$, or dTC on ciliary cell survival (see above), and may be due to the unexpected blockade of choroid ganglionic transmission. This hypothesis is supported by the observations of neuronal survival following a lower dose of atropine, which does not block ganglionic transmission and does not appear to decrease choroid neuron survival. The smooth muscle environment of the choroid coat may not respond to paralysis in a manner that compensates for the effects of ganglionic blockade, decreasing neuronal survival after chronic atropine treatment in the same way that chlorasondamine and dTC decrease choroid cell survival. This inability of atropine to increase peripheral support for cloroid motoneurons may be due to an activityindependent competition for survival among these neurons. Furthermore, Meriney and Pilar (1987) found that the onset of effective cholinergic transmission in the choroid (St 36-39) is later than the onset of normal neuronal death (St 34). This reinforces observations that the smooth muscle target's functional innervation is not involved in choroid cell survival.

Unexpectedly, daily nicotinic receptor blockade with $\alpha \mathrm{BTX}$ has variable effects on choroid cell survival, depending on the dose used, and these effects are independent of influences on either ganglionic or neuromuscular transmission. Low doses of $\alpha \mathrm{BTX}(12.5 \mu \mathrm{g} / \mathrm{d})$ decrease choroid survival by $21 \%$, while higher doses of $\alpha$ BTX ( $75 \mu \mathrm{g} / \mathrm{d}$ ) increase choroid cell survival by about $100 \%$. We are not aware of any interactions between $\alpha \mathrm{BTX}$ and muscarinic $\Lambda \mathrm{ChRs}$, and therefore we have no explanation for the opposite effects of low and high doses of $\alpha$ BTX. The higher dose of $\alpha$ BTX may work by influencing cell survival in the choroid cell population by an as-yet unknown activity-independent mechanism, or indirectly by increasing trophic factor production in the nearby ciliary body target region, where complete striated muscle blockade exists throughout the injection period in the "high-dose"-treated embryos. This could cause an overall increase in trophic factor within the eye, resulting in a higher concentration in the vicinity of the choroid nerve terminals as well. Accordingly, H. Fryer, S. D. Meriney, and G. Pilar (unpublished observations) have found a dramatic, but transient, 3-fold increase in soluble ciliary neuronotrophic factor in the $\alpha$ BTX-treated whole eye at St 37 . Alternatively, there may be $\alpha \mathrm{BTX}$ binding sites in the choroid environment that influence neuronal survival independent of synaptic activity.

In summary, the effects on cell survival in the ciliary ganglion after chronic AChR blockade cannot always be predicted by the target muscle activity hypothesis developed for the spinal cord. Blockade of transmission through the ciliary ganglion increases cell death in both populations of neurons. Neuromuscular blockade at striated muscle synapses delays neuronal death in the spinal cord and ciliary cell population, but not in the choroid cell population, where neuromuscular synapscs are made with smooth muscle. It is possible that smooth muscle does not respond to synaptic blockade in a manner that supports more neuronal survival. Furthermore, choroid cell survival can be influenced by $\alpha \mathrm{BTX}$, which does not block transmission at the choroid neuromuscular junction.

\section{Mechanisms involved in the competition for survival}

Since the effects of AChR blockade on neuronal survival in the ciliary ganglion cannot always be predicted by the target muscle activity hypothesis developed for the spinal cord, the site of action of these effects on neuronal survival must be reevaluated. We have shown that blockade of ganglionic transmission can influence ciliary ganglion cell survival, indicating that neuromuscular interactions are not the only site for the regulation of neuron number during development. Cunningham (1982) proposed that motoneurons must "balance" afferent input with target connections during a critical period after both afferent and neuromuscular synapses are made. Our results support this hypothesis. Since the AChR blockers used in this study influence activity at both ganglionic and target synapses, it is important to define and evaluate the effects of activity blockade in both 
target neuromuscular and preganglionic environments in order to further our understanding of normal neuronal death.

First, electrical activation of ganglion neurons by presynaptic ACh release may regulate the amount of trophic factor taken up in the target region. Blocking motoneuron activation may decrease "support" to the ganglion cells by precluding an activity-dependent uptake mechanism for target-derived trophic factors.

Second, blockade of activity at neuromuscular synapses prevents action potentials from being initiated in muscle cells. Neuromuscular transmission may act through the activation of muscle fibers to regulate the availability of a putative trophic factor in the target region. Denervation has been shown to increase NGF production by the rat iris (Ebendal et al., 1980), independent of an equivalent increase in NGF mRNA (Shelton and Reichardt, 1985). NGF is known to have a trophic effect on sensory and sympathetic neuronal survival (Levi-Montalcini and Angeletti, 1963; Hamburger and Yip, 1984). It is possible that the chick iris, ciliary body, and choroid produce a soluble or membrane-bound trophic factor that regulates parasympathetic neuronal survival in a manner similar to that of NGF. Barbin et al. (1984) have purified a factor from chick eye tissues that supports ciliary ganglion survival in vitro. We predict from our results that striated muscular activity will decrease the availability of trophic support, while paralysis will increase it. Interestingly, limb muscle homogenates of denervated muscle maintain more motoneuron survival in vitro than do control limb muscle homogenates, and this effect can be reversed by direct limb muscle stimulation (Hill and Bennett, 1986). Accordingly, the ability of $\alpha \mathrm{BTX}$, dTC, and atropine to increase ciliary neuron survival may be due to the effects of target muscle paralysis on trophic support for these neurons.

Although atropine paralyzes choroid smooth muscle, the decrease in choroid neuron survival observed with higher doses of atropine may be due to both the unexpected ganglionic blockade and the apparent inability of this target muscle to increase support to these neurons (possibly because of peripheral activity-independent neuronal death). Creedon and Tuttle (1986) report that, unlike striated muscle (Nishi and Berg, 1977), vascular smooth muscle is unable to provide the support necessary for long-tcrm survival of ciliary ganglion ncurons in vitro. Finally, in another recent report (Abrahamson et al., 1986), it has been shown that survival of motoneurons innervating the smooth muscle of the expansor secundariorum is independent of the presence of that target. Trophic support from an apparently NGF-like substance is derived from the non-neuronal cells in the nerve sheath (Abrahamson et al., 1986).

Non-neuronal elements may also be involved in the process of neuronal elimination at the level of the neuromuscular junction. Neuronal terminals are surrounded by non-neuronal cells, some of which remove dying cells by phagocytosis. In addition, there are a variety of blood-borne phagocytic cells that normally respond to immunologic signals. The drug treatments that influence neuronal survival may modify the function of these nonneuronal cells such that their phagocytotic activity is increased or decreased. Macrophages, for example, are known to possess several receptor types (including AChRs) that can influence their function (Coffey and Hadden, 1985). At present, however, we have no evidence that this interaction occurs at either choroid or iris neuromuscular junctions.

As has been described for target cells, preganglionic terminals themselves may directly provide activity-dependent trophic support. Presynaptic input has been implicated in the metabolic regulation of postsynaptic neurons. Transsynaptic enzyme regulation is known to occur after surgical denervation or changes in afferent activity, and may also influence long-term motoneuron survival. Pilar et al. (1973) demonstrated that in the ciliary ganglion, the integrity of the presynaptic terminal is required to maintain normal $\mathrm{ACh}$ metabolism; this was later shown to be due to the transsynaptic regulation of CAT activity in the postsynaptic cells (Giacobini et al., 1979). Similarly, preganglionic denervation of sympathetic ganglia (which receive cholinergic input, but synthesize norepinephrine) decreases AChE activity (Giacobini et al., 1967), tyrosine hydroxylase (TH), and dopamine- $\beta$-hydroxylase (DBH) activity (Hendry et al., 1973; Black, 1974), while an increase in nervous activity of the sympathetic ganglia increases $\mathrm{TH}$ and DBH activity in postganglionic cells. Also, neuropeptides have been shown to influence enzyme activity in the superior cervical ganglion (Zigmond, 1985). The possibility exists that transsynaptic trophic signals in the avian ciliary ganglion are the neuropeptides (substance $\mathrm{P}$ and opiates) present in the presynaptic terminals (Erichsen et al., 1982). Recently, morphine (an opiate agonist) has been shown to increase the survival of both populations of ciliary ganglion neurons (Meriney et al., 1985), independent of any effects on target muscle activity (Meriney and Pilar, 1985). However, an endogenous peptide regulation of neuronal survival has not yet been demonstrated.

In summary, the level of activity at both preganglionic and neuromuscular synapses appears to contribute to the trophic support for developing ciliary ganglion neurons. Blockade of striated muscle activity may increase trophic support to innervating motoneurons, while blockade of ganglion cell activity may either decrease the ability of these neurons to take up trophic support in the target, or prevent a preganglionically released transsynaptic trophic substance from reaching the motoneurons. The choroid peripheral environment may not respond to blockade by increasing support to innervating motoneurons for several reasons. It is possible that few close neuromuscular contacts exist during the normal cell death period (see Meriney and Pilar, 1987). In addition, the level of endogenous activity in choroid neurons may be very low, while ciliary nerve activity may be present at a constant rate during the cell death period. In both cases, blockade of a postsynaptic $\mathrm{AChR}$ in the choroid coat would not be expected to affect the neuromuscular interactions regulating choroid neuron death.

Although we have limited our discussion of the consequences of activity blockade to effects on neuromuscular or ganglionic interactions, it is also possible that these treatments directly influence the central activation of motoneurons, as has recently been shown in the spinal cord by Landmesser and Szente (1986). We do not know, however, if any of the AChR blockers influence central activation patterns in the midbrain.

Other aspects of neuromuscular and ganglionic synapse formation may also regulate long-term neuronal survival. We feel that the relative importance of nerve terminal sprouting, synaptic contact, and synapse formation has not been given equal emphasis in the context of neuronal survival. Pharmacological muscle paralysis has been shown to increase nerve terminal sprouting. Conversely, the activation of muscle cells causes the retraction of sprouting (Brown et al., 1981). Whether these interactions are based on release of trophic substances or on direct membrane-membrane recognition (Tuttle, 1983), the amount of neuronal contact with the target is probably important. More 
terminals provide more surface area for uptake of a trophic factor, and/or more apposition of nerve and muscle membranes for contact-mediated interactions. Immature neuromuscular junctions in the developing iris have been shown to be characterized by occasional close apposition of nerve and muscle membranes (Pilar et al., 1981). Similarly, smooth muscle neuromuscular junctions in the posthatch choroid coat also occasionally display such appositions. We have not yet investigated the nerve-muscle ultrastructural relationships in the choroidal tissue during the normal neuronal death period. An absence of close synaptic contacts in the embryonic choroid coat may account for the difference between ciliary and choroid neuronal survival following AChR blockade. The important neuromuscular interaction following peripheral paralysis may depend on a contact-mediated regulation of neuronal death. We are actively pursuing this line of investigation, but these experiments are beyond the scope of this paper. Although we have presented several hypotheses, the mechanisms regulating the differential cell survival in the ciliary ganglion in response to blockade of smooth versus striated muscle activity are not known at this time.

Our results confirm the role of activity in regulating neuronal survival at striated synapses, but question the general applicability of this hypothesis to neuronal populations that innervate nonstriated muscle targets.

\section{References}

Abercrombie, M. (1946) Estimation of nuclear population from microtome sections. Anat. Rec. 94: 239-247.

Abrahamson, I. K., P. A. Wilson, and R. A. Rush (1986) Production and transport of endogenous trophic activity in a peripheral nerve following target removal. Dev. Brain Res. 27: 117-126.

Barbin, G., M. Manthorpe, and S. Varon (1984) Purification of the chick eye ciliary neuronotrophic factor. J. Neurochem. 43: 14681478

Beaudoin, A. R. (1955) The development of lateral motor column cells in the lumbo-sacral cord in Rana pipiens. I. Normal development and development following unilateral limb ablations. Anat. Rec. 121: $81-96$.

Bergey, G. K., S. C. Fitzgerald, B. K. Schrier, and P. G. Nelson (1981) Neuronal maturation in mammalian cell culture is dependent on spontaneous electrical activity. Brain Res. 207: 49-58.

Black, I. B. (1974) Growth and development of cholinergic and adrenergic neurons in a sympathetic ganglia. In Dynamics of Degeneration and Growth in Neurons, K. Fuxe, L. Olson, and L. Zotterman, eds., pp. 455-467, Pergamon, Elmsford, N.Y.

Boydston, W. R., and G. S. Sohal (1979) Grafting of additional periphery reduces embryonic loss of neurons. Brain Res. 178: 403-410.

Brown, M. C., R. L. Holland, and W. G. Hopkins (1981) Motor nerve sprouting. Annu. Rev. Neurosci. 4: 17-42.

Chiappinelli, V. A., and E. Giacobini (1978) Time course and appearance of alpha-bungarotoxin binding sites during development of chick ciliary ganglion and iris. Neurochem. Res. 3: 465-478.

Chiappinelli, V. A., and R. E. Zigmond (1978) $\alpha$-Bungarotoxin blocks nicotinic transmission in the avian ciliary ganglion. Proc. Natl. Acad. Sci. USA 75: 2999-3003.

Coffey, R. G., and J. W. Hadden (1985) Ncurotransmitter hormones and cyclic nucleotides in lymphocyte regulation. Fed. Proc. 44:112117.

Connor, E. A., S. M. Levy, and R. L. Parsons (1983) Kinetic analysis of atropine-induced alterations in bullfrog ganglionic fast synaptic currents. J. Physiol. (Lond.) 337: 137-158.

Cowan, W. M., J. W. Fawcett, D. D. M. O'Leary, and B. B. Stanfield (1984) Regressive events in neurogenesis. Science 225: 1258-1265.

Creedon, D. J., and J. B. Tuttle (1986) Failure of vascular smooth muscle to support the survival of cultured ciliary ganglion neurons. Soc. Neurosci. Abstr. 12: 1111

Cunningham, T. J. (1982) Naturally occurring neuron death and its regulation by developing neural pathways. Int. Rev. Cytol. 74: 163186.

Ebendal, T., L. Olson, A. Seiger, and K.-O. Hedlund (1980) Nerve growth factors in the rat iris. Nature $286: 25-28$.

Erichsen, J. T., H. J. Karten, W. D. Eldred, and N. C. Brecha (1982) Localization of substance P-like and enkephalin-like immunoreactivity within preganglionic terminals of the avian ciliary ganglion: Light and electron microscopy. J. Neurosci. 2: 994-1003.

Freeman, S. S., A. G. Engel, and D. B. Drachman (1976) Experimental acetylcholine blockade of the neuromuscular junction. Effects on endplate and muscle fiber ultrastructure. Annu. NY Acad. Sci. 274: 4659.

Furber, S., and R. W. Oppenheim (1984) Increased neuron death in the chick embryo ciliary ganglion following deafferentation. Soc. Neurosci. Abstr. 10:640.

Giacobini, E., B. Palmborg, and F. Sjoqvist (1967) Cholinesterase activity in innervated and denervated sympathetic ganglion cells of the cat. Acta Physiol. Scand. 69: 355-361.

Giacobini, E., G. Pilar, J. Suszkiw, and II. Uchimura (1979) Normal distribution and denervation changes of neurotransmitter related enzymes in cholinergic terminals. J. Physiol. (Lond.) 286: 233-253.

Hamburger, V. (1934) The effects of wing bud expirtation on the development of the central nervous system in chick embryos. J. Exp. Zool. 68: 449-494.

Hamburger, V., and H. L. Hamilton (1951) A series of normal stages in the development of the chick embryo. J. Morphol. 88: 49-92.

Hamburger, V., and J. W. Yip (1984) Reduction of experimentally induced neuronal death in spinal ganglia of the chick embryo by nerve growth factor. J. Neurosci. 4: 767-774.

Hendry, I. A., L. L. Iversen, and I. B. Black (1973) A comparison of the neural regulation of tyrosine hyroxylase activity in sympathetic ganglia of adult mice and rats. J. Neurochem. 20:1683-1689.

Hill, M. A., and M. R. Bennett (1986) Motoncurone survival activity in extracts of denervated muscle reduced by prior stimulation of the muscle. Dev. Brain Res. 24: 305-308.

Hollyday, M., and V. Hamburger (1976) Reduction of naturally occurring motorneuron loss by enlargement of the periphery. J. Comp. Neurol. 170: 311-320.

Landmesser, L., and G. Pilar (1972) The onset and development of transmission in the chick ciliary ganglion. J. Physiol. (Lond.) 222: 691-713.

Landmesser, L., and G. Pilar (1974) Synaptic transmission and cell death during normal ganglionic development. J. Physiol. (Lond.) 241: 737-749

Landmesser, L., and M. Szente (1986) Activation patterns of embryonic chick hindlimb muscles following blockade of activity and motoneuron cell death. J. Physiol. (Lond.) 380:157-174.

Levi-Montalcini, R. (1949) The development of the acoustico-vestibular centers in the chick embryo in the absence of the afferent root fibers and of descending fiber tracts. J. Comp. Neurol. 91: 209-242.

Levi-Montalcini, R., and P. U. Angeletti (1963) Essential role of nerve growth factor in the survival and maintenance of dissociated sensory and sympathetic embryonic nerve cells in vitro. Dev. Biol. 7: 653659.

Loring, R. H., V. A. Chiappinelli, R. E. Zigmond, and J. B. Cohen (1984) Characterization of snake venom neurotoxin which blocks nicotinic transmission in the avian ciliary ganglion. Neuroscience 11: 989-999.

Marwitt, R., G. Pilar, and J. N. Weakly (1971) Characterization of two ganglion cell populations in avian ciliary ganglion. Brain Res. 25: 317-334

Meriney, S. D., and G. Pilar (1985) Chronic morphine administration delays normal cell death in the avian ciliary ganglion. Soc. Neurosci. Abstr. 11:260.

Meriney, S. D., and G. Pilar (1987) Cholinergic innervation of the smooth muscle cells in the choroid coat of the chick eye and its development. J. Neurosci. 7: 3827-3839.

Meriney, S. D., G. Pilar, and R. Nuñez (1984) The effects of chronic neuromuscular blockade and cGMP administration on differential motoneuron survival in the avian ciliary ganglion. Soc. Neurosci. Abstr. 10: 640 .

Meriney, S. D., D. B. Gray, and G. Pilar (1985) Morphine-induced delay of normal cell death in the avian ciliary ganglion. Science 228 : $1451-1453$

Nishi, R., and D. K. Berg (1977) Dissociated ciliary ganglion neurons 
in vitro: Survival and synapse formation. Proc. Natl. Acad. Sci. USA 74: 5171-5175

Okada, N., and R. W. Oppenheim (1984) Cell death of motoneurons in the chick embryo spinal cord. IX. The loss of motoneurons following removal of afferent inputs. J. Neurosci. 4: 1639-1652.

Oppenheim, R. W., and I.-W. Chu-Wang (1977) Spontaneous cell death of spinal motoneurons following peripheral innervation in the chick embryo. Brain Res. 125: 154-160.

Pilar, G., D. J. Jenden, and B. Campbell (1973) Distribution of acetylcholine in the normal and denervated pigeon ciliary ganglion. Brain Res. 49: 245-256.

Pilar, G., L. Landmesser, and L. Burstein (1980) Competition for survival among developing ciliary ganglion cells. J. Neurophysiol. 43: 233-254.

Pilar, G., J. Tuttle, and K. Vaca (1981) Functional maturation of motor nerve terminals in the avian iris: Ultrastructure, transmitter metabolism, and synaptic reliability. J. Physiol. (Lond.) 321: 175-193.

Pilar, G., R. Nuñez, I. S. McLennan, and S. D. Meriney (1987) Muscarinic and nicotinic synaptic activation of the developing chicken iris. J. Neurosci. 7: 3813-3826.

Pittman, R. H., and R. W. Oppenheim (1978) Neuromuscular blockade increases motorneurone survival during normal cell death in the chick embryo. Nature 271: 364-366.

Pittman, R. H., and R. W. Oppenheim (1979) Cell death of motor- neurons in the chick embryo spinal cord. IV. Evidence that a functional neuromuscular interaction is involved in the regulation of naturally occurring cell death and the stabilization of synapses. J. Comp. Neurol. 187: 425-446.

Shelton, D. L., and L. F. Reichardt (1985) Denervation of rat iris does not increase the level of mRNA encoding beta nerve growth factor Soc. Neurosci. Abstr. 11: 939.

Sohal, G. S., T. C. Creazzo, and T. G. Oblak (1979) Effects of chronic paralysis with $\alpha$-bungarotoxin on development of innervation. Exp. Neurol. 66: 619-628.

Tuttle, J. B. (1983) Interaction with membrane remnants of target myotubes maintains transmitter sensitivity of cultured neurons. Science 220: 977-979.

Tuttle, J. B., J. Suszkiw, and M. Ard (1980) Long-term survival and development of dissociated parasympathetic neurons in culture. Brain Res. 183: 161-180.

Wright, L. (1981) Cell survival in the chick ciliary ganglion is reduced by chronic ganglionic blockade. Dev. Brain Res. 1: 283-286.

Zenker, W., and E. Krammer (1967) Untersuchungen uber Feinstruktur und Innervation der inneren Augenmuskulatur des Huhnes. $Z$. Zellforsch. 83: 147-168.

Zigmond, R. E. (1985) Biochemical consequences of synaptic stimulation: The regulation of tyrosine hydroxylase activity by multiple transmitters. Trends Neurosci. 8: 63-69. 